\title{
Impact of Lockdown During COVID-19 Outbreak on Ophthalmological Emergency in a Reference Center in France
}

Rim MAALEJ ( $\sim$ rmaalej@for.paris )

Rothschild Foundation: La Fondation Adolphe de Rothschild

Rabih HAGE

Rothschild Foundation: La Fondation Adolphe de Rothschild

Flore Salviat

Rothschild Foundation: La Fondation Adolphe de Rothschild

Catherine VIGNAL

Rothschild Foundation: La Fondation Adolphe de Rothschild

\section{Research Article}

Keywords: COVID-19 pandemic, Ophthalmic Emergency Department, eye, lockdown

Posted Date: July 9th, 2021

DOI: https://doi.org/10.21203/rs.3.rs-443510/v1

License: (a) (i) This work is licensed under a Creative Commons Attribution 4.0 International License.

Read Full License 


\section{Abstract}

\section{Purpose}

In March 2020, the sudden rise in number of SARS-CoV2 infections in France let the government to impose a strict lockdown during which all non-urgent medical consultations were postponed. From March 17 to May 10, 2020, private medical practices were closed and telemedicine was encouraged. The consequences on ophthalmic care were dramatic with over $90 \%$ of scheduled consultations canceled.

The aim of this study was to report the consultation during the 2-month strict lockdown in Paris and to analyze its impact on the visual outcomes of patients consulting in the ophthalmology emergency department (OED)

Methods :

Data of patients who presented to the OED of the A. de Rothschild Foundation Hospital (RFH), a tertiary ophthalmology center in Paris, France, during the lockdown period and its immediate aftermath were analyzed. The results were compared to the same time periods in the years of 2018 and 2019. Four time periods were defined and numbered chronologically: March 17 to May 10, 2018 (Period 1) ; March 17 to May 10, 2019 (Period 2); March 17 to May 10, 2020 (Period 3, the lockdown period); May 11 to June 9, 2020 (Period 4, the post-lockdown period)

Results :

The number of consultation was reduced by more than $50 \%$ during the lockdown period $(n=2909$ patients) and by $30 \%$ during the post-lockdown period $(n=2622)$ when compared to periods $1(n=7125)$ and $2(n=8058)$ Even though LP4 saw an increase in the number of consulting patients, there was no raise in the rate of severe diseases (12.8\% during LP3 vs $11.1 \%$ during LP4) and the proportion of patients who were padmitted was statistically similar (4.3\% VS 3.6\%). Neuro-ophthalmic -diseases were the most common during LP3 and LP4. Neovascular glaucoma were twice as common during post LP4 $(p=0.08)$. We highlighted a significant increase in patients with a graft reject consulting in our OED during the post LP4 $(p<0.001)$. Those results were likely related to a delay in the follow-up consultations due to the lockdown measures.

\section{Conclusion}

The reduction in the number of consultations in our OED during the lockdown period did not focus mainly on minor emergencies and also affected severe ophthalmic diseases with no significant delay in consultation. More longitudinal and longer study is needed to confirm this and to analyze retrospectively the COVID-19 outbreak and lockdown effects.

\section{Introduction}


Visual loss and ocular pain are the most common reasons for patients to seek medical attention in an eye-dedicated emergency unit[1]. In the vast majority of cases, these symptoms are related to benign causes. However, in some patients, they might represent the first manifestation of sight-threatening systemic diseases. Unfortunately, there is no proportional relationship between the intensity of visual symptoms and the severity of the disease. For instance, a benign corneal scratch, which causes unbearable pain, can heal quickly, and leave no visual impairment. On the other hand, intermittent double vision can reveal giant cell arteritis that can lead to retinal ischemia and permanent visual loss. In this last case scenario, patients may postpone medical consultation, mistakenly thinking that those intermittent, painless symptoms are either mild or irrelevant. It is easy to understand how environmental situation like the weather or a situation of sanitary emergency like a lockdown might increase the delay for those patients to consult. In France, the first COVID-19 lockdown began on March 17, 2020 and came with severe movement restriction measures. All non-urgent medical appointments were postponed and people were able to be outside of their house only for 1 hour per day. A great number of ophthalmology clinics were closed. However, access to the ophthalmic emergency department was always possible. . We aimed to establish whether the Covid-19 lockdown had affected the eye care, the visual prognostic and general health prognostic in patients who presented to our Eye Emergency Unit. To achieve this goal, we reviewed the files of patients who presented during the lockdown and its immediate aftermath, and compared them to those of patients who had consulted in the same time period as the lockdown, in the previous two years.

\section{Methods}

We conducted a retrospective study at the A. de Rothschild Foundation Hospital (RFH), a tertiary center of ophthalmic emergencies and neuro-ophthalmology in Paris, France. Data of patients who presented to the ophthalmic emergency department (OED) during the lockdown period and its immediate aftermath were analyzed. The results were compared to the same time periods in the years of 2018 and 2019.

Four time periods were defined and numbered chronologically: March 17 to May 10, 2018 (Period 1, P1) ; March 17 to May 10, 2019 (Period 2, P2); March 17 to May 10, 2020 (Period 3, the lockdown period, P3); May 11 to June 9, 2020 (Period 4, the post-lockdown period, P4)

The study was approved by the Ethical Committee of the Hospital. N CE_20200602_5_CVT

\section{Data collection:}

The files of all patients consulting at the OED during these time periods were reviewed. Every patient had comprehensive ophthalmic examination. The following data were collected: demographics, hour of presentation, chief complaint, time of onset of symptoms, and COVID-19 symptoms, if any. 
Depending on the presentation, additional examinations were performed. They included blood tests, OCT, MRI, CT scan, and ultrasound. Follow up examination was collected when available.

\section{Categorization}

For each patient, the severity of the presentation was categorized using the Basic Severity Score for Common Ocular Emergencies (BaSe SCOrE) [2]. This score was elaborated to weigh ocular emergency events according to their severity. On a scale of 1 to 5 , the most severe diseases are rated 4 or 5

According to this score, the most severe diseases are the following:

- Open globe injuries, post-operative hemorrhage, graft rejection, perforated ulcer.

- Retinal vasculitis, foveal or papillary toxoplasmosis, foveal choroidal neovascularization, central retinal artery occlusion, central venous occlusion

- Acute angle closure glaucoma, neovascular glaucoma

- Retinal detachment, endophtalmitis, panophtalmitis.

- Neuro-ophthalmological abnormalities: paralytic diplopia with or without anisocoria, optic neuropathies whatever the mechanism: inflammation, ischemia, compression....

Patients presenting visual field defects related to a stroke or a brain tumor were also included in the in the severe-disease group.

Statistical Analyses

We used the Statistical Package for Social Sciences (SPSS) 20. (IBM Corporation, Armonk, NY). Categorical variables were presented as frequency and percentages, continuous variables were presented as mean and standard deviation for normally distributed variables or median and IQR for non-normally distributed variables. Continuous data across groups were compared using Mann-Whitney U test or t-test as appropriate, categorical data were compared using Chi-square tests. P values of $<0.05$ indicated statistical significance.

\section{Results}

From March $17^{\text {th }}, 2020$ to June $9^{\text {th }}, 2020(P 3+P 4)$, a total of 5531 patients consulted in the OED.

Nine patients were tested positive to SARS-CoV2. Two of them were diagnosed with retinal tear , 1 with retinal detachment, 1 with anterior uveitis, 1 with E coli endogenous endophtalmitis, 1 with Terson syndrome, 1 with fever and cough and 1 patient was admitted for a stroke. One patient presented a posterior ischemic optic neuropathy after an admission to the intensive care unit.

During the lockdown period (P3), 2909 patients visited the OED (52.9 patients per day on average $($ median $=52$, standard deviation $=15.9))$. Amongst them, 126 patients $(4.3 \%)$ were admitted as 
in-patients, and 637 (21.8\%) had an out-patient clinic follow-up (Table 1).

OED attendance increased in the post lockdown period, with a total of 2622 patients (87.3 patients per day, median $=89.5$, standard deviation=13.6) (Figure1). Amongst them, 94 patients $(3.6 \%)$ were admitted, and 518 (19.7\%) had an out-patient clinic follow-up (Figure2).

The distribution of daily consulting patients according to the period is detailed in Table 2.

The patients' demographic characteristics in both periods are presented in Table3. The distribution of severe diseases during and after the lockdown is presented in Table 4.

During P3 and P4, there were respectively 373/2909 (12.8\%) and 291/2622 (11.1\%) patients presenting with severe diseases, according to the BaSe SCOrE. A third of them consulted for neuro-ophthalmic disorders.

In 2018 (period 1), there were 7125 patient visits, of which 266 (3.7\%) led to an admission to the hospital. In 2019 (period 2), there were 8058 patient visits, of which 223 (2.7\%) led to an admission to the hospital (Table 1).

Among the severe diseases, retinal detachment was less frequent in 2020 during the 8 weeks of P3 ( $n=$ $44 ; 1.5 \%)$ compared to the same period in $2018(n=314 ; 4.4 \%)$ and $2019(n=287 ; 3.5 \%)$; this difference was statistically significant $(p<0.001)$. Interestingly the percentage of patients with a diagnosis of retinal detachment did not increase during the 4 first weeks of the post lockdown P4 ( $n=36 ; 1.3 \%)$.

Seven patients said they delayed their visit to the OED because of the lockdown or because they were afraid of catching the virus by going outside of their house. The average delay was of 19 days (1 to 60).

In our cohort, one woman was a victim of severe domestic abuse during the lockdown.

\section{Discussion}

Since December 2019, the global pandemic caused by SARS-CoV-2 has induced unprecedented changes in medical practice [3].

The lockdown that began in France on March 17, 2020 induced a remarkable and a disturbing decrease in ophthalmic emergency department visits.

RFH is a hospital dedicated to head and neck diseases. During P3, its organization changed dramatically to accommodate patients with COVID-19 in medicine and intensive care units. The outpatient clinic closed, but the OED and the Stroke Unit remained open. The overall number of OED attendances have approximately halved during the lockdown (P3) which is consistent with the drop in the overall number of patients presenting to the emergency departments. The significant decrease in the number of consultations in P3, greater during the second and the third week, was explained by the fear to catch the virus by hospital attendance, the fine for breaking confinement rules, the reduction in public 
transportation, and the fact that some patients were confined at home or tested positive to the virus. Also, the decrease in outside activity can explain the reduction of minor emergencies such as conjunctivitis or corneal foreign body, which are the most frequent causes for consultation in emergency. The reduction in the number of conjunctivitis can also be explained by hygiene measures such as frequent hand washing, social distancing, and the lower frequency of wearing contact lenses during the lockdown period.

During P4, we noticed an increase of total visits (87 per day VS 52 in P3). However, neither the proportion of patients consulting for severe disease ( $12.8 \%$ during P3 vs $11.1 \%$ after), nor the proportion of admitted patients for the more severe emergencies was significantly different (4.3\% VS 3.6\%). This stability is maybe related the absence of significant consultation delay for patients with severe ophthalmic diseases. However, the considered post lockdown period of 4 weeks could be too short to highlight such a delay. We also could hypothesize that there was a balance between decrease in severe emergencies and increasing in other emergencies during these 2 periods. Compared to Period 1 and 2, the number of daily consultations was reduced by more than $50 \%$ in P3 and by $30 \%$ in P4, suggesting that people were still afraid of the virus after the lockdown period. However, the rate of hospital admission in 2018, 2019, and 2020 was stable. This stable rate seems low but is similar to the rate reported in an eye related emergency department in the USA (2.8\%)[4] Another large retrospective American study of more than 370 000 people reported that $23 \%$ of enrolled visited the OED for non-urgent ocular condition and only $6.7 \%$ had severe ocular pathologies, but there is no mention of how many patients were hospitalized[5].

In a recent publication coming from Taiwan concerning more than 5000 patients consulting an eye related emergency department, $10.3 \%$ were admitted to the ophthalmology ward[1].

These differences may be related to the emergency consultation habits, which vary from one country to another.

We didn't notice a significant rise of the average age after the lockdown $(p=0.50)$, suggesting that, if needed, elderly people visited the OED during P3 and P4; furthermore, during P3, the absence of trauma related to outdoor activities was balanced by the relative rise of domestic injuries.

Among the severe diseases, neuro-ophthalmic diseases (optic neuropathies, idiopathic intracranial hypertension, pupil abnormalities...) and the visual manifestations of stroke were the most common, which can be explained by the specificity of our hospital specialized in neuro-ophthalmology combined with a stroke Unit. Their proportion did not differ during P3 and after. However, more MRIs were performed in emergency during P3 ( $n=187: 6.4 \%)$ than after (P4: $n: 127: 4.8 \%)$; this difference is statically significant $(p<0,001)$ and may be explained by the fact that during the $P 3$, new procedures were used to avoid multiple consultations and extended medical workup to be performed at time of presentation, when needed[6]. The number and proportion of MRI performed in the same period in $2018(0.9 \%)$ and 2019 $(1.6 \%)$ is lower, which can be explained both by the changes in the diagnostic and treatment protocols, but also by the acquisition of 2 additional 3T-MRI allowing faster acquisition protocols, which made their use more frequent. 
However, among the other severe ophthalmic diseases, and even if the number of patients is not high for each pathology, we found that the proportion and the number of some pathologies are quite different between the 2 periods $\mathrm{P} 3$ and $\mathrm{P} 4$ :

Neovascular glaucoma were twice as common during post lockdown period, which suggested a delay in the consultations for central venous occlusions $(p=0.08)$.

Likewise, the significant increase in patients with a graft reject consulting in our OED during post lockdown period $(p<0.001)$ could be linked to a delay in the follow-up consultations of the corneal grafts performed before.

Conversely, the frequency of the open globe injuries decreases by half during P4 compared to P3 $(p=0.03)$, probably because of a decrease in "do it yourself work" at home. Because of the cancellation of during P3, no endophthalmitis was observed in the month following the lockdown.

Compared to 2018 and 2019, the rate and number of surgical retinal detachments during the P3 was significantly lower $(p<0.001)$. This can be related to the decrease of outdoor activities and reduction of trauma, or to delays in patients' presentation. The same low rate was seen at the start of P4, suggesting that this could be explained by the reduction of sports and violence with a progressive resumption of outdoor activities, but, again a period of 4 weeks may be too short to affirm the absence of delay of consultation.

Two other European studies, concerning the impact of COVID-19 pandemic and lockdown on eye emergencies have been published recently. In both articles, the authors compare the lockdown period in 2020 with an equivalent period in 2019. In the United Kingdom[7]and in Italy[8] the authors reported a reduction in the number of consultations similar to ours, i.e. around $50 \%$ and no difference in the demographic profile of the patients. Similarly, in the UK study, there was a significant reduction in the number and the overall incidence of retinal detachment in 2020 vs. 2019 while vitreo-retinal disorders increased in the Italian study. The recruitment of these two centers is however different from ours, since neuro-ophthalmologic emergencies are much less frequent. A third study concerning the same period was published in India[9], with different demographic characteristics, i.e., $30 \%$ of children and $73.5 \%$ of male patients consulting in emergency during the lockdown. In this study, the eye emergency services decreased by $32.25 \%$, with and increasing proportion of microbial keratitis and conjunctivitis amplified by 1.25 times 2 times, respectively.

Our study had some limitations: some patients groups are small, the P4 is short, and the return to a normal activity happened gradually, which does not allow us to conclude firmly on the possible existence of consultation delays, their importance and their impact in terms of loss of chance; finally, we did not compare all the categories of severe ocular emergencies in the same period of 2018, 2019 and 2020.

\section{Conclusion}


To the best of our knowledge this is the largest report of the impact of COVID-19 lockdown on the ophthalmological emergencies. Surprisingly, the reduction in the number of consultations in our ophthalmological emergencies unit during the lockdown period did not concern only minor emergencies. It also affected severe ophthalmic diseases. The number of patients presenting to the emergency room gradually increased over the next 4 weeks after P3 without any obvious delay over this short period. We didn't notice irreversible visual damages secondary to a delay of consultation. More longitudinal and longer study is needed to confirm this and to analyze retrospectively the COVID-19 outbreak and lockdown effects.

\section{Declarations}

Funding : Not applicable

Conflicts of interest/Competing interests : Not applicable

Availability of data and material : Yes

Code availability : Not applicable

Ethics approval : The research was approved by the Rothschild Foundation Hospital review board - IRB $n^{\circ} 00012801$

Consent to participate : Not applicable

Consent for publication : Not applicable

\section{References}

1. Yu-Chuan Khang E, Tai Jui-Y WC, Huang CJ et al. Eye-related Emergency Department Visits with Ophthalmology Consultation in Taiwan; Visual Acuity as an Indicator of Ocular Emergency. Sci Rep 2020;10 : 98

2. Bourges JL, Boutron I,Monnet D et al. Consensus on Severity for Ocular Emergency: The BAsic SEverity Score for Common OculaR Emergencies [BaSe SCOrE].J Ophthalmol. 2015; 2015: 576983.

3. WHO. Rolling updates on coronavirus disease (COVID-19), https://www.who.int/emergencies/diseases/novel-cor- onavirus-2019/events-as-they-happen (accessed 10 May 2020).

4. Vaziri K, Schwartz SG, Flynn Jr HW et al. Eye-related Emergency Department Visits in the United States, 2010. Ophtalmology. 2016 Apr;123(4):917-9.

5. Stagg BC,Shash MM, Talwar N, Padovani-Claudio DA, Woodward MA, Stein JD.Factors Affecting Visits to the Emergency Department for Urgent and Nonurgent Ocular Conditions.Ophthalmology. 2017 May;124(5):720-729. 
6. Defoort S, Lamirel C, Touitou V, Vignal C. Neuro-ophthalmologic emergencies during this COVID-19 pandemic. J Fr Ophtalmol. 2020 Jun;43(6):550-55.

7. 7.Poyser A, Deol SS, Osman L et al. Impact of COVID-19 pandemic and lockdown on eye emergencies. Eur J Ophthalmol. 2020 Nov 19:1120672120974944.

8. 8.Franzolin E, Casati S, Albertini $O$ et al. Impact of Covid-19 pandemic on Ophthalmic Emergency Department in an Italian tertiary eye centre. Eur J Ophthalmol. 2021 Feb 25:1120672121998223.

9. 9.Agarwal R, Sharma N Patil A, Thakur H et al. Impact of COVID-19 pandemic, national lockdown, and unlocking on an apex tertiary care ophthalmic institute. Indian J Ophthalmol. 2020 Nov;68 (11):2391-2395.

\section{Tables}

Table 1: Management of patients during and after consulting in the eye-related emergency department at the Adolphe de Rothschild Foundation (Paris, France) according to the period

\begin{tabular}{|c|c|c|c|c|c|c|}
\hline & & $\begin{array}{l}\text { Period } \\
1^{\text {a }} \\
\text { (8 } \\
\text { weeks) }\end{array}$ & $\begin{array}{l}\text { Period } \\
2^{\text {b }} \\
\text { (8 } \\
\text { weeks) }\end{array}$ & $\begin{array}{l}\text { Lockdown } \\
\text { period } 3^{c} \\
\text { (8 weeks) } \\
n=2909\end{array}$ & $\begin{array}{l}P \\
\text { value }^{d}\end{array}$ & $\begin{array}{l}\text { Post } \\
\text { Lockdown } \\
4^{\mathrm{e}} \\
\text { (4 weeks) }\end{array}$ \\
\hline & & $n=7125$ & $n=8058$ & $\mathrm{n}(\%)$ & & $n=2622$ \\
\hline & & n (\%) & n (\%) & & & $\mathrm{n}(\%)$ \\
\hline \multirow{2}{*}{$\begin{array}{l}\text { Management of } \\
\text { patients after } \\
\text { consulting in the eye- } \\
\text { related emergency } \\
\text { department }\end{array}$} & Hospitalization & $\begin{array}{l}266 \\
(3.7)\end{array}$ & $\begin{array}{l}223 \\
(2.8)\end{array}$ & $126(4.3)$ & 0.006 & $94(3.6)$ \\
\hline & Ambulatory & $\begin{array}{l}6859 \\
(96.3)\end{array}$ & $\begin{array}{l}7835 \\
(97.2)\end{array}$ & $\begin{array}{l}2783 \\
(95.7)\end{array}$ & & $\begin{array}{l}2528 \\
(96.4)\end{array}$ \\
\hline \multirow[t]{2}{*}{ Performed MRI } & Yes & $\begin{array}{l}64 \\
(0.9)\end{array}$ & $\begin{array}{l}131 \\
(1.6)\end{array}$ & $187(6.4)$ & $<0.001$ & $127(4.8)$ \\
\hline & No & $\begin{array}{l}7061 \\
(99.1)\end{array}$ & $\begin{array}{l}7927 \\
(98.4)\end{array}$ & $\begin{array}{l}2722 \\
(93.6)\end{array}$ & & $\begin{array}{l}2495 \\
(95.2)\end{array}$ \\
\hline \multirow[t]{2}{*}{ Performed CT-scan } & Yes & $\begin{array}{l}38 \\
(0.5)\end{array}$ & $\begin{array}{l}80 \\
(1.0)\end{array}$ & $40(1.4)$ & 0.005 & $22(0.8)$ \\
\hline & No & $\begin{array}{l}7087 \\
(99.5)\end{array}$ & $\begin{array}{l}7978 \\
(99.0)\end{array}$ & $\begin{array}{l}2869 \\
(98.6)\end{array}$ & & $\begin{array}{l}2600 \\
(99.2)\end{array}$ \\
\hline
\end{tabular}

Abbreviation: MRI: magnetic resonance imaging

CT: computerized tomography 
${ }^{\mathrm{a} F r o m ~} 03 / 17 / 2018$ to $05 / 10 / 2018$

${ }^{b}$ From $03 / 17 / 2019$ to $05 / 10 / 2019$

${ }^{\mathrm{C}}$ From $03 / 17 / 2020$ to $05 / 10 / 2020$

${ }^{\mathrm{d}} \mathrm{Chi}^{2}$ test comparing the mean of the proportions of both periods 1 and 2 versus the proportions of period 3

eFrom $05 / 11 / 2020$ to $06 / 09 / 2020$

Table 2: Distribution of daily emergency consulting patients according to the period

\begin{tabular}{lllllllll} 
& Average & $\begin{array}{l}\text { Standard } \\
\text { deviation }\end{array}$ & Min & Q1 & Median & Q3 & Max & $\begin{array}{l}\text { N } \\
\text { days }\end{array}$ \\
\hline $\begin{array}{l}\text { Lockdown period } \\
\text { P3 }\end{array}$ & 52.9 & 15.9 & 26.0 & 40.5 & 52.0 & 64.5 & 91.0 & 55
\end{tabular}

Post lockdown

87.4

13.6

$\begin{array}{lll}65.0 & 76.25 & 89.5\end{array}$

98.75

11730 period $\mathrm{P} 4^{\mathrm{b}}$
a P3 from $03 / 17 / 2020$ to $05 / 10 / 2020$
b P4 from 05/11/2020 to 06/09/2020

Table 3: Patient characteristics during and after the lockdown period 


\begin{tabular}{|c|c|c|c|}
\hline & $\begin{array}{l}\text { During the lockdown period } \mathrm{P}^{\mathrm{a}} \\
(\mathrm{n}=2909)\end{array}$ & $\begin{array}{l}\text { Post- lockdown period P4 } \\
(n=2622)\end{array}$ & $P$ value \\
\hline \multicolumn{4}{|l|}{ Sex, n (\%) } \\
\hline Male & $1484(51.5)$ & $1357(52.4)$ & \\
\hline Female & 1399 (48.5) & $1231(47.6)$ & \multirow[t]{2}{*}{$0.48^{*}$} \\
\hline Missing & 26 & 34 & \\
\hline \multicolumn{4}{|l|}{ Age in years } \\
\hline Mean (SD) & $45.4(22.6)$ & $45.6(23.0)$ & $0.92 * \star$ \\
\hline Median (range) [IQR] & $47.0(1.0-99.0)$ [29.0-63.0] & $46.0(1.0-99.0)[29.0-64.0]$ & \\
\hline Missing & 62 & 52 & \\
\hline \multicolumn{4}{|l|}{ Children, n (\%) } \\
\hline Yes (age < 15 years) & 338 (11.9) & $290(11.3)$ & $0.50 *$ \\
\hline No (age $\geq 15$ years) & 2509 (88.1) & $2280(88.7)$ & \\
\hline
\end{tabular}

*Chi square test

** Wilcoxon-Mann-Whitney test

a P3 from $03 / 17 / 2020$ to $05 / 10 / 2020$

b P4 from $05 / 11 / 2020$ to $06 / 09 / 2020$

Table 4: Distribution of severe diseases during and after the COVID-19 lockdown 


\begin{tabular}{|c|c|c|c|}
\hline Diagnosis, n (\%) & $\begin{array}{l}\text { During the lockdown } \\
\text { period }^{\text {a }}\end{array}$ & $\begin{array}{l}\text { After the lockdown } \\
\text { period }^{\text {b }}\end{array}$ & $\begin{array}{l}P \\
\text { value }\end{array}$ \\
\hline & $(n=373)$ & $(n=291)$ & \\
\hline $\begin{array}{l}\text { Neurology and neuro- } \\
\text { ophthalmology }\end{array}$ & $194(52.0)$ & $144(49.5)$ & $0.71^{d}$ \\
\hline Others ${ }^{c}$ & $127(34.0)$ & $104(35.7)$ & $0.65^{d}$ \\
\hline Oculomotor nerve palsy & $33(8.8)$ & $21(7.2)$ & $0.45^{d}$ \\
\hline Optic neuritis & $21(5.6)$ & $14(4.8)$ & $0.64^{d}$ \\
\hline Stroke & $13(3.5)$ & $5(1.7)$ & $0.16^{d}$ \\
\hline Retina and posterior segment & $139(37.3)$ & $108(37.1)$ & $0.98^{d}$ \\
\hline Retinal detachment & $44(11.8)$ & $36(12.4)$ & $0.82^{d}$ \\
\hline $\begin{array}{l}\text { Foveal choroidal } \\
\text { neovascularization }\end{array}$ & $34(9.1)$ & $34(11.7)$ & $0.28^{d}$ \\
\hline $\begin{array}{l}\text { Retinal vasculitis, foveal or } \\
\text { papillary } \\
\text { toxoplasmosis }\end{array}$ & $25(6.7)$ & $14(4.8)$ & $0.30^{d}$ \\
\hline Central vein occlusion & $19(5.1)$ & $19(6.5)$ & $0.43^{d}$ \\
\hline Central retinal artery occlusion & $10(2.7)$ & $5(1.7)$ & $0.41^{d}$ \\
\hline Endophthalmitis & $7(1.9)$ & $0(0.0)$ & $0.02^{\mathrm{e}}$ \\
\hline Corneal and anterior segment & $40(10.7)$ & $39(13.4)$ & $0.35^{d}$ \\
\hline Open globe injury & $20(5.4)$ & $6(2.1)$ & $0.03^{d}$ \\
\hline Acute angle closure glaucoma & $9(2.4)$ & $5(1.7)$ & $0.54^{d}$ \\
\hline Neovascular glaucoma & $7(2.4)$ & $14(4.8)$ & $0.03^{d}$ \\
\hline Corneal graft reject & $3(0.8)$ & $14(4.8)$ & $0.001^{d}$ \\
\hline Perforated ulcer & $1(0.3)$ & $0(0.0)$ & $1.0^{\mathrm{e}}$ \\
\hline
\end{tabular}

a P3 from 03/17/2020 to $05 / 10 / 2020$

b P4 from 05/11/2020 to 06/09/2020 
${ }^{c}$ including acute anterior ischemic optic neuropathy, compressions, intracranial hypertension, anisocoria, and diplopia not related to oculomotor nerve palsy

${ }^{\mathrm{d}}$ Chi square test ${ }^{\mathrm{e}}$ Fisher's exact test

\section{Figures}

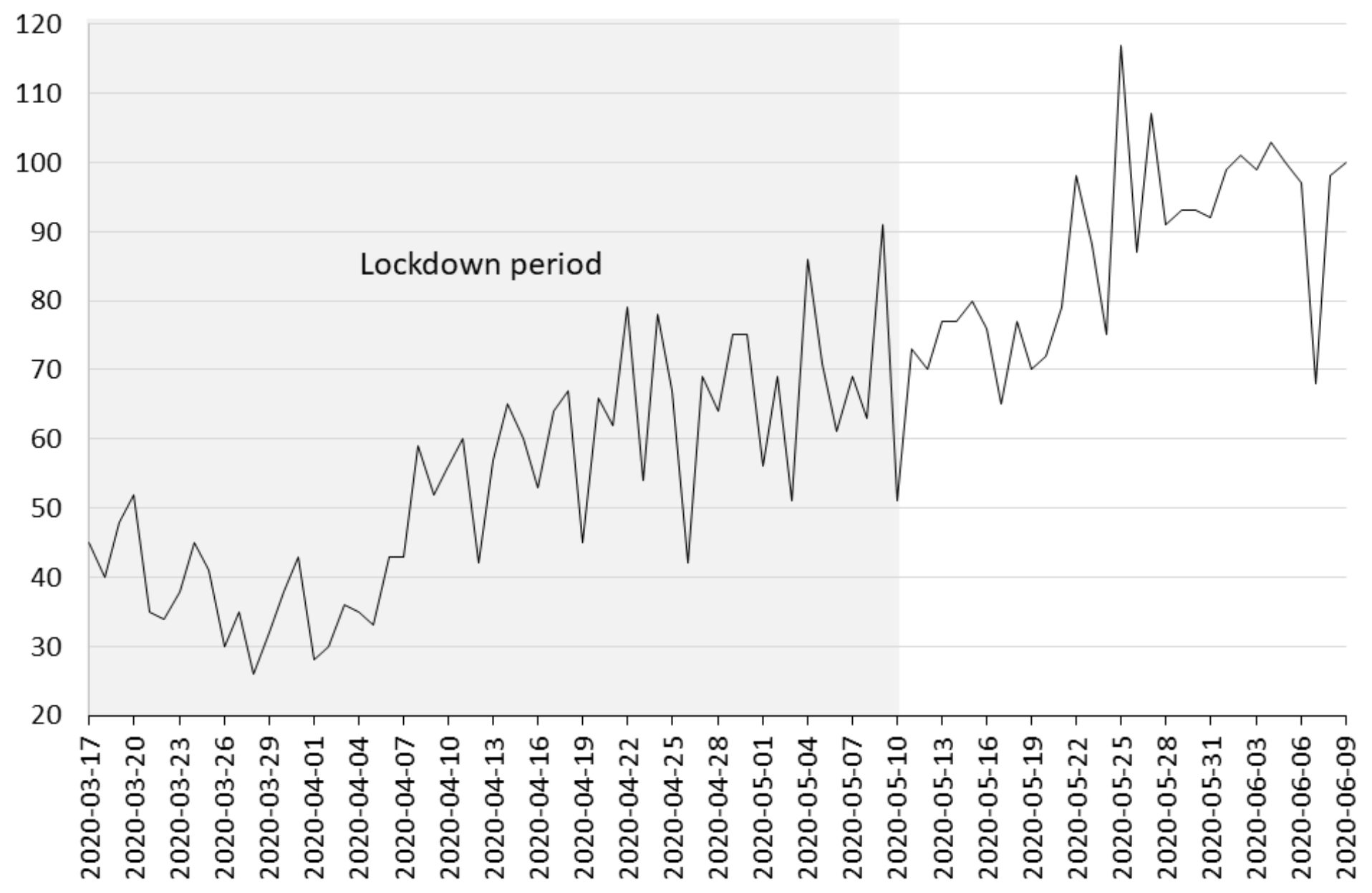

\section{Figure 1}

Amongst them, 126 patients (4.3\%) were admitted as in-patients, and 637 (21.8\%) had an out-patient clinic follow-up (Table 1). OED attendance increased in the post lockdown period, with a total of 2622 patients (87.3 patients per day, median=89.5, standard deviation=13.6) 


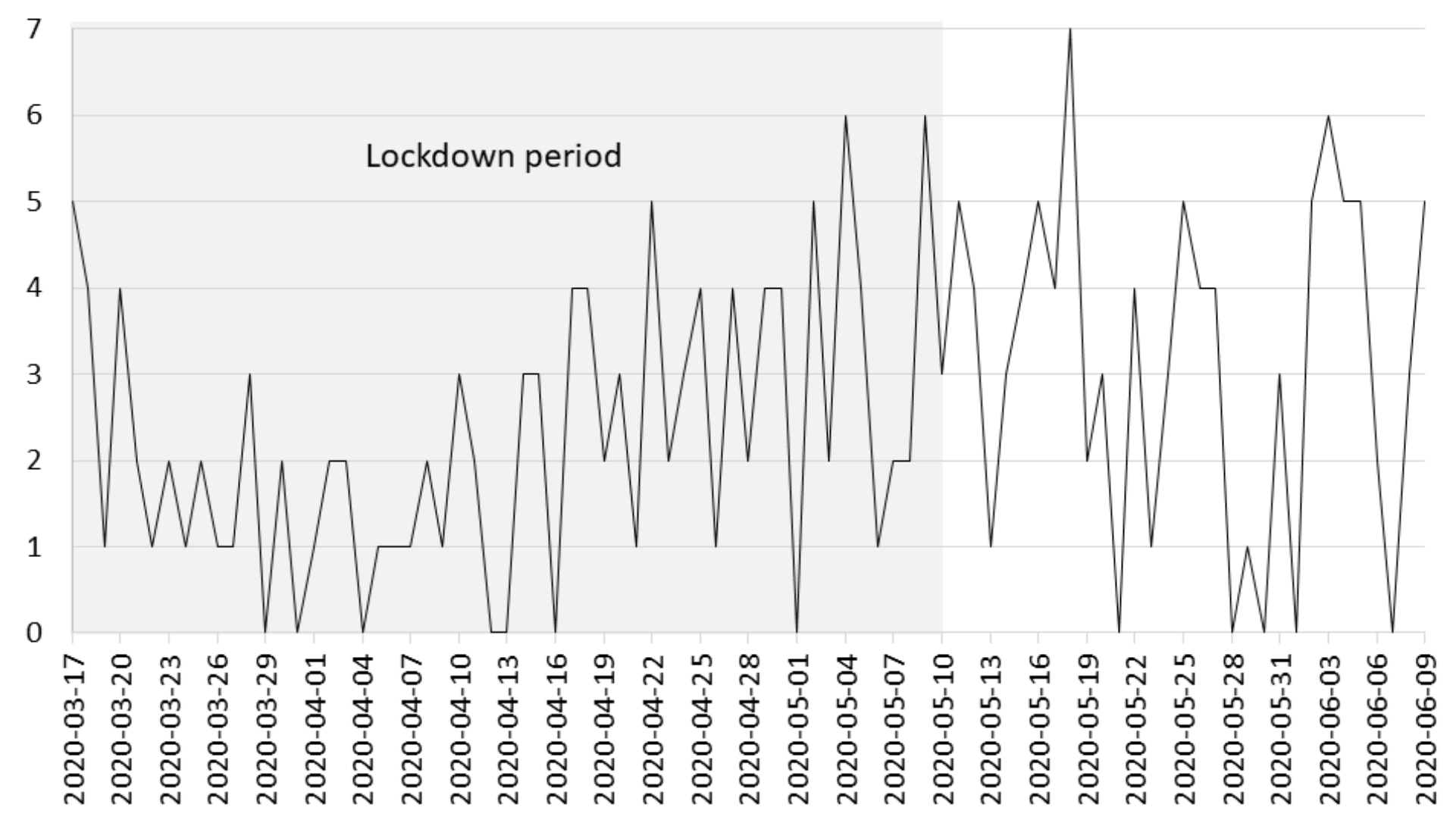

Figure 2

Amongst them, 94 patients (3.6\%) were admitted, and 518 (19.7\%) had an out-patient clinic follow-up 